\title{
Determinants of overweight with concurrent stunting among Ghanaian children
}

\author{
Benedicta K. Atsu' ${ }^{1}$ Chris Guure ${ }^{2}$ and Amos K. Laar ${ }^{1 *}$
}

\begin{abstract}
Background: Malnutrition (undernutrition and overnutrition) is a major public health problem in Ghana -affecting growth and development of individuals and the nation. Stunting and overweight are of particular interest, as recent national surveys show a rising trend of overnutrition and stubbornly high burden of stunting among Ghanaian children. There are currently no data on the simultaneous occurrence of overweight and stunting within individuals in Ghana. This paper presents the burden, the individual-level, and contextual determinants of overweight with concurrent stunting among Ghanaian children.

Methods: This study analyzed data set of the fourth round of the Ghana Multiple Indicator Cluster Survey (MICS4). Bivariate analyses were used to describe selected characteristics of survey respondents and their children. Hierarchical modelling approach facilitated identification of significant distal, intermediate and proximal factors/determinants of concurrent stunting and overweight. Both crude and adjusted prevalence ratios via a multivariable Poison regression model with their corresponding 95\% Confidence Intervals (Cl) are reported. Variables with $p \leq 0.25$ at the bivariate level were included in the multivariable analysis. An alpha value of $5 \%$ was used to indicate significance.
\end{abstract}

Results: Of 7550 cases (children) analyzed, the prevalence of stunting was 27.5\%; underweight was 17.3\%; and wasting was $7.7 \%$. The prevalence of overweight and concurrent overweight and stunting were respectively $2.4 \%$ and $1.2 \%$. Children who belonged to the fourth wealth quintile, were more likely to be overweight and concurrently stunted as against children belonging to the poorest quintile ( $a P R=1.010 ; 95 \% \mathrm{Cl}, 1.003-1.017$ ). Compared to religious (Christians/Muslim/Traditionalist) household heads, children whose household heads did not belong to any religion had 2 times the rates of the Overweight with concurrent stunting ( $P R=2.024 ; 95 \% \mathrm{Cl}, 1.016-4.034)$. Children with mothers aged 20-34 and 35-49 had an increased though insignificant prevalence ratio of association $(\mathrm{aPR}=1.001 ; 95 \% \mathrm{Cl}, 0.994-1.005)$ and $(\mathrm{aPR}=1.001 ; 95 \% \mathrm{Cl}, 0.998-1.012)$ respectively.

Conclusion: This analysis determined the prevalence of concurrent stunting and overweight among Ghanaian children to be $1.2 \%$. Four contextual variables (breastfeeding status, religion, geographic region, and wealth index quintile) were associated with overweight with concurrent stunting. We conclude that, only contextual factors are predictive of DBM among children under five living in Ghana.

Keywords: Stunting, Overweight, Overweight with concurrent stunting, Undernutrition, Overnutrition and children under-five, Ghana

\footnotetext{
*Correspondence: alaar@ug.edu.gh

${ }^{1}$ Department of Population, Family and Reproductive Health, School of

Public Health, College of Health Sciences, University of Ghana, Accra, Ghana

Full list of author information is available at the end of the article
}

(c) The Author(s). 2017 Open Access This article is distributed under the terms of the Creative Commons Attribution 4.0 International License (http://creativecommons.org/licenses/by/4.0/), which permits unrestricted use, distribution, and reproduction in any medium, provided you give appropriate credit to the original author(s) and the source, provide a link to the Creative Commons license, and indicate if changes were made. The Creative Commons Public Domain Dedication waiver (http://creativecommons.org/publicdomain/zero/1.0/) applies to the data made available in this article, unless otherwise stated. 


\section{Background}

Child growth is an important public health indicator for monitoring nutritional status and health in populations [1]. Information on undernutrition prevalence in children is a proximate indicator of the overall nutritional and food security conditions in a country [2]. Children at the start of their life have greater nutritional needs owing to the rapid pace of their growth [3]. It has been established that early malnutrition begins in utero during the early embryonic and fetal development stages, where the developing fetus soley depends on its genotype and the materno-fetal environment [4]. This period is characterised with increased energy demands to meet the metabolic demands of pregnancy [5]. Undernutrition and overnutrition, which we now know can originate from early chilhhood [4] can lead to the death of many young children [6] as well as onset of nutrition related illness or other complications later in life [1].

Although the prevalence of overnutrition in Ghana has not reached epidemic proportions [7] - in comparison with countries from the developed world, there is evidence of an alarming upward trend in many developing countries [8]. The change in Ghanaian lifestyles and consumption patterns are contributing factors to inadequate growth coupled with excess weight gain $[9,10]$. The economic, demographic, environmental and cultural changes are known determinats of the changes in lifestyles and consumption patterns reported in other industrial countries with increased overnutrition rates [11]. Infections and social determinats are key determinats of undernutrition [12].

Overweight with concurrent stunting coexist at individual levels, national and community levels, and within households [13-20]. Concurrency of overweight and stunting has been found to exist in children in rural Mexico, Peru, Russia, Brazil, South Africa and China [21-23]. A key determinant is fetal undernutrition especially during the first thousand days of life [4]. Other distal level determinants are poor environmental conditions and overpopulation [24]. Double burden of malnutrition increases the risk of mortality, morbidity and poor cognitive development. Poor health and development in early life can limit the educational, social and economic achievements of individuals across their life span and increase the risk of poor adult health $[25,26]$. The determinants, as well as the biochemical and environmental bases of the linkage between childhood nutritional stunting and various adverse outcomes have been explored. For instance, childhood nutritional stunted has been shown to be associated with impaired fat oxidation, a factor that predicts obesity in other at-risk populations [27]. In later years of life, stunting and overweight, directly or indirectly affects the child's growth, socially, emotionally, morally and academically [27]. In addition, birth interval, size at birth [28]; type of birth whether multiple or single births [29, 30]; ethnicity [31]; sex, type of residence and limited access to safe drinking water [32]; genetic factors, [31] among some others, were found to be determinants of stunting.

Determinants of overweight as reviewed from literature include; parental overweight [32, 33]; a male child with a young overweight mother [23]; age and household composition [34] occupation of the mother and mother's BMI [35]; socioeconomic class and ethnic variables [36] family size and income $[37,38]$.

The factors associated with concurrent stunting and overweight have been indentifed elsewhere and include maternal height, age, education, household size, and lower socioeconomic status [11, 21, 23, 39]; sex, age in months, urban-rural residence, geographic region, maternal education and household wealth [40]; rural or urban setting and sanitation, [23]. Put togeher, concurrency of stunting and overweight is influenced by socioeconomic, demographic, and environmental factors [28].

Ghana records significant numbers of both undernutrition and overnutrition [7]. Commonly referred to as the double or dual burden of malnutrition, the coexistence of contrasting forms of malnutrition is fast becoming major public health problem in both developed and developing country settings [7, 9, 41-44]. A country with high burdens of underweight, stunting, and overweight, is assumed to be in its stages of nutrition transition [41]. Children under five are most susceptible to this condition $[39,44]$. Nationally representative Ghanaian surveys (DHS, MICS) report coexistence of the stunting and overweight in the Ghanaian commuity, but not within individuals. The current study aimed to assess the prevalence of overweight with concurrent stunting, and its individual and contextual determinants among Ghanaian children.

\section{Methods \\ Design and study sites}

The study was a secondary data analysis of nationally representative survey [7].The current analysis assessed the prevalence of overweight with concurrent stunting among Ghanaian children under five and determined the individual and contextual determinants of overweight with concurrent stunting. The Ghana MICS collected data from all 10 regions in Ghana which included rural and urban settlements with randomly selected households.

\section{Study population, inclusion and exclusion criteria}

This study made use of data collected from women (1549 years) and children ( $0-5$ years). The study's population was the MICS sample of selected households. The study made use of data obtained from households where children under five were identified. Data used in this analysis include; household data, birth history, women's data and 
children's data obtained from their mothers or primary caretakers.

\section{Sample size and sampling}

The study made use 7550 children for whom complete interview responses were obtained from their mothers or caregivers during the MISC4 survey. This study employed the sampling and sampling size procedures as explained in the Ghana MICS 2011 report.

The MICS4 sample survey used a random two-stage sample survey, (multi-stage, stratified cluster sampling approach). The first stage of the survey dealt with the selection of Primary Sampling Units (PSUs) from a sampling frame which was the list of the 2010 Ghana Population and Housing Census Enumeration areas (EAs). The 2010 Population and Housing census was used for the selection of clusters. Census EAs were defined as PSU. The second stage dealt with the selection of the Secondary Sampling Units (SSUs) which was the selection of households from each selected EA in first stage. PSUs were selected from each of the sampling strata using systematic Probability Proportional Sample (PPS) based on estimated sizes of the EA from the 2010 Population Census. Each region in Ghana, is made up of two strata: the urban and the rural areas. The total number of strata was therefore 20 for the whole country. Sample selection and estimation were conducted separately in each stratum. With the list of households from the 2010 Population Census, the total number of households in each selected cluster (Enumeration Area) was sequentially numbered from 1 to $\mathrm{n}$ at the Ghana Statistical Service; and then the selection of 15 households in each cluster was carried out using random systematic selection procedures. Households sample size calculation formula

$$
n=\frac{4 r(1-r) f(1+t)}{(0.12 r)^{2} h p} \quad \mathrm{n}=810
$$

Where:

$\mathrm{n}=$ the minimum number of households to be

interviewed $(95 \% \mathrm{CI})$

$\mathrm{r}^{2}=2006$ MICS value for the indicator

$\mathrm{r}=$ expected rate for the indicator for 2011

$\mathrm{f}=$ design effect for the indicator in MICS 2006

$\mathrm{t}=$ non response rate for households in MICS 2006

$\mathrm{h}=$ average household size in 2006 MICS

$\mathrm{p}=$ proportion of children aged 12-23 months among

the total population.

This result suggested that for each region taken as domain the household sub sample size was 810 . Details can be found in the MICS 2011 report.

\section{Variables}

This study assessed the prevalence and determinants of overweight with concurrent stunting among children under-five years. Guided by previous studies [6, 23, 40, 45-48], explanatory variables were evaluated using bivariate and regression analysis. The variables were grouped into factors such as; distal, intermediate and proximal following $[49,50]$.

\begin{tabular}{ll}
\hline Distal factors & Intermediate factors \\
Child's characteristics & - Sources of drinking water \\
- Sex of household head & - Marital status \\
- Religion of household head & - Maternal age at child birth \\
- Ethnicity of household head & - Size of child at birth \\
- Maternal education & - Birth order \\
- Wealth index quintile & - Area of residence \\
- Mosquito net utilization & - Geographic zones \\
Proximal factor & - Three northern and \\
• Breastfeeding status & non-northern regions \\
- Child with diarrhea & - Child taken to a health facility \\
- Child with cough & during illness \\
- Child given Vitamin A dose within & - Child ever received any \\
last 6 months & vaccinations \\
& - Anemia status \\
& Other Factors -NHIS status \\
& - Age and Sex of child \\
\hline
\end{tabular}

\section{Measurement of nutritional status}

The nutritional status of the children were measured using HAZ, WAZ, WHZ and BMIZ with consultation to the new cut-offs based on the 2006 WHO growth standards. Children whose appropriate height, weight were not recorded and with HAZ below -6 or above +6 ; WAZ below -6 or above +5 : WHZ below -5 or above +5 and BMIZ below -5 or above +5 were excluded from the analysis [44]. HAZ, WAZ, WHZ and BMIZ which were continuous variables were categorized into mildly, moderately, or severely stunted, underweight and wasted whereas BMIZ was categorized into overweight and obese.

A child was regarded as mildly stunted, underweight or wasted if HAZ, WAZ and WHZ were less than two standard deviation (-1.00SD to $-1.99 \mathrm{SD})$ from the median reference population. Consequently, children were categorized as moderately or severely stunted, underweight or wasted if HAZ, WAZ and WHZ were two $(-2.00 S . D$ to $-2.99 S . D)$ or above three $(<-3.00 S D)$ standard deviations from the median of the reference population. Conversely, a child was considered as overweight and obese if BMIZ was greater than two (> +2.00S.D) standard deviations from the median of the reference population. For the purpose of this study both obese and overweight children were referred to as overweight. Children who were moderately and severely stunted, and wasted were computed into stunting $(<-2.00 \mathrm{SD})$ and wasting 
$(<-2.00$ S.D $)$ variables. A child who is simultaneously overweight and stunted was considered as having BMIZ > +2.00 S.D. and HAZ below -2.00 SD computed into a variable named concurrency. The stunting, overweight and concurrency variables were dichotomized into being overweight and concurrently stunted or not. Univariate analysis was used to generate descriptive tabulations for key variables assessed from the MICS dataset. The background and socio-demographic variables were grouped under the assessed characteristics. The sex specific prevalence nutritional status of children were computed.

\section{Statistical analysis}

Statistical analyses of the MICS4 data set were performed using IBM SPSS Statistics for Windows version 20.0. Key variables identified in the data sets for this study's analysis were transformed into either categorical or dichotomized variables. Variables that were categorized included religion and ethnicity of the household head, sources of drinking water, size of child at birth, the ten regions of Ghana and children's hemoglobin level. Child anemia status was dichotomized into anemic or normal. Children were dichotomized into either having cough, diarrhea or not. Malaria rapid test results were also dichotomized into whether the child's test was positive or negative.

Both bivariate and multivariable approaches were used to obtain prevalence ratios (PR). This was implemented using a Poison regression with a robust estimation of the variance to obtain prevalence ratios (PR) with a $95 \%$ confidence interval. The justification for fitting the Poison model instead of the logistic regression model was due to the focus of the study (nutritional status of children under-five). The simple and multiple Poison regression modeling approach produced unadjusted/crude and adjusted associations between each of the key outcome variable and selected characteristics. In the simple regression model, each of the selected characteristics were assessed independently with the outcome variable. The multiple Poison regression model took into consideration the hierarchical nature of the risk factors. There is the likelihood of distal (socio-economic and other variables) factors affecting either directly or indirectly all the other potential risk factors except age and sex. This was followed by the intermediate factors and then the proximal factors.

The analysis were considered in three different ways. The first was the unadjusted prevalence ratios followed by adjustment at only factor level (where distal factors are adjusted for without including proximal or intermediate factors) and lastly the hierarchical adjustment. In the hierarchical adjusted approach, the first model (model-1) considered only age and sex of the child and model- 2 contained model- 1 with the distal factors adjusted for. The other models were similarly obtained with the final model which contains all the factors and the other variables presented in Table 4. Significant relationships were denoted with an asterisk $(*)$. **** and ${ }^{* * *}$ denoted statistical significance at $p<0.001$ and $<0.01$, while * denoted statistical significance at $p<0.05$. The multiple Poison regression model was developed for selected characteristics that were significant at $p<0.25$ as well as those recommended by literature.

\section{Results}

Tables 1, 2, 3, and 4 present the background characteristics, and nutrition status of children under 5 years, assembled under; distal, intermediate and proximal factors as well as the child's age and sex. A little over $50 \%$ of the sampled children were males (51.1\%) and were between 36 and 47 months of age (21.2\%). Christian household heads constituted about $48 \%$, followed by Muslims, (31.5\%), Traditionalists (14.2\%) and other religions (6.4\%). Also, most of the household heads were from Ghanaian northern tribes (60.6\%). About $63.5 \%$ of the sampled women were married. Mothers with no formal education constituted, $54.1 \%$ with the least being $7.2 \%$ having a secondary education and or higher. Most of the under-fives and their household heads lived in rural areas (72\%) especially in the northern geographical zone (54.6\%).

\section{Nutritional status of children}

Out of the total number of 7550 children $97.2 \%$ were included in the stunting analysis. Similarly, 97.9, 97.8, 97.1 and $96.6 \%$ included in the underweight, wasting, BMI calculation and overweight with concurrent stunting analysis. Under-fives whose height, weight and age were correctly recorded were included in the analysis. About $30 \%$ of the Ghanaian children were malnourished. The most prevalent form of malnutrition was stunting $(27.5 \%)$ followed by underweight, (17.3\%) wasting $(7.7 \%)$ and overweight and obesity (2.4\%). Overall, the prevalence of overweight with concurrent stunting was $1.2 \%$. Most of the children under five were mildly stunted, mildly underweight and mildly wasted. Comparatively more males than females were stunted, underweight, wasted, overweight and anaemic (Details are presented in Table 2).

\section{Predictors of overweight with concurrent stunting (focus on age, sex and the distal factors)}

Tables 1, 2 and 3 present the simple and multiple Poison regression modelling of overweight with concurrent stunting under the distal, intermediate and proximal factors. Included in these tables are the age and sex of the children that are not affected by either of these three factors. The selected characteristics are displayed together with their unadjusted prevalence ratios and factors specific adjusted measures of association. The 
Table 1 Sex specific nutritional status of children under 5 according to four anthropometric indices, height for age, weight for age, weight for height and Body Mass Index

\begin{tabular}{|c|c|c|c|}
\hline Characteristics & Overall n (\%) & Male n (\%) & Female $\mathrm{n}(\%)$ \\
\hline \multicolumn{4}{|l|}{ Stunting } \\
\hline Mildly stunted & $2287(31.1)$ & $1144(15.6)$ & $1143(15.6)$ \\
\hline Moderately stunted & $1355(18.5)$ & $740(10.1)$ & $615(8.4)$ \\
\hline Severely stunted & $667(9.1)$ & $380(5.2)$ & $287(3.9)$ \\
\hline Stunting (below -2 SD) & $2022(27.5)$ & $1120(15.3)$ & $902(12.3)$ \\
\hline Total & 7342 & & \\
\hline \multicolumn{4}{|l|}{ Underweight } \\
\hline Mildly underweight & $2348(31.8)$ & $1197(16.2)$ & $1151(15.6)$ \\
\hline Moderately underweight & $973(13.2)$ & $528(7.1)$ & $445(6.0)$ \\
\hline Severely underweight & $306(4.1)$ & $186(2.5)$ & $120(1.6)$ \\
\hline Underweight (below -2SD) & $1279(17.3)$ & $714(9.7)$ & $565(7.6)$ \\
\hline Total & 7395 & & \\
\hline \multicolumn{4}{|l|}{ Wasting } \\
\hline Mildly wasted & $1547(21.0)$ & $787(10.7)$ & $760(10.3)$ \\
\hline Moderately wasted & $448(6.1)$ & $270(3.7)$ & $178(2.4)$ \\
\hline Severely wasted & $118(1.6)$ & $75(1.0)$ & $43(0.6)$ \\
\hline High weight for height & $144(2.0)$ & $86(1.2)$ & $58(0.8)$ \\
\hline Wasting (below -2SD) & $566(7.7)$ & $345(4.7)$ & $221(3.0)$ \\
\hline Total & 7381 & & \\
\hline \multicolumn{4}{|l|}{ Body Mass Index } \\
\hline Overweight/obese (> +2SD) & $178(2.4)$ & $103(1.4)$ & $75(1.0)$ \\
\hline Overweight & $130(1.8)$ & $80(1.1)$ & $50(0.7)$ \\
\hline Obese & $48(0.7)$ & $23(0.3)$ & $25(0.3)$ \\
\hline Total & 7328 & & \\
\hline Concurrency & $88(1.2)$ & $51(0.7)$ & $37(0.5)$ \\
\hline Total & 7293 & & \\
\hline \multicolumn{4}{|l|}{ Anemia status } \\
\hline Normal & 1535 (34.0) & 710 (15.7) & 825 (18.3) \\
\hline Mild anemic & $1036(22.9)$ & $526(11.6)$ & $510(11.3)$ \\
\hline Moderate anemic & 1756 (38.9) & $888(19.7)$ & $868(19.2)$ \\
\hline Severe anemic & $190(4.2)$ & $127(2.8)$ & $63(1.4)$ \\
\hline Total & 4517 & & \\
\hline
\end{tabular}

Mildly: $z$-score - 1.00SD to -1.99SD; moderately: z-scores $-2.00 \mathrm{SD}$ to $-2.99 \mathrm{SD}$; severely: z-score less than 3.00SD; overweight: z- score + 2.00SD to 2.99SD and obese -z-score greater than 3.00SD. Normal-11 g/dl and above; mild anemia$10 \mathrm{~g} / \mathrm{dl}-10.9 \mathrm{~g} / \mathrm{dl}$; moderate anemia-7 g/dl - $9.9 \mathrm{~g} / \mathrm{dl}$; severe anemia- less than $7 \mathrm{~g} / \mathrm{dl}$

hierarchical modelling of all the factors presented according to levels (from Model-1 to Model-4) are in Table 5.

The results of the Poison regression model showed that the overall rates overweight with concurrent stunting with increasing age of a child was not statistically significant. However, children aged 11-23 months compared to 0-11 months were less likely to be concurrently stunted with overweight (aPR $=0.990$; 95\% CI, 0.982-0.999). Although not reaching statistical significance, the prevalence ratio of overweight with concurrent stunting was lower among girls compared to their male counterparts $(\mathrm{PR}=0.754 ; 95 \% \mathrm{CI}, 0.495-1.149)$. After adjusting for potential confounders at factor-specific and the overall model adjustment levels, female children were more likely to beconcurrently stunted and overweight, $(\mathrm{aPR}=1.003 ; 95 \% \mathrm{CI}, 0.998-1.007)$, although this was not statistically significant. Also no significant changes were observed for increasing age at the model specific adjusted rate ratios. Children whose household heads did not belong to any religion had more than twice the rates of those from the Christian religion $(\mathrm{PR}=2.024$, $95 \%$ CI, 1.016, 4.034) and this was statistically significant. Though Traditional and the Islamic religions were not statistically significant, both had higher rates of overweight and concurrent stunting than their Christian religious colleagues Table 1. After factor-specific adjustments of prevalence ratios, not belonging to any religion was was associated with reduced likelihood to experience concurrent stunting and overweight $(\mathrm{aPR}=0.987 ; 95 \% \mathrm{CI}$, $0.974-1.002)$. Of note, this was statistically significant after adjustements (see adjusted prevalence ratio of 1.020 with 95\% confidence interval of (1.002-1.038) under Model-4 in Table 5). Compared to the poorest quintile, children belonging to the fourth index quintile had a significantly increased rates of overweight with concurrent stunting $(\mathrm{aPR}=1.010$; 95\% CI, 1.010-1.017.

\section{Predictors of overweight with concurrent stunting with Intermediate factors}

Although not statistically significant, children sampled from the rural areas were more likely to be concurrently stunted and overweight compared to those from the urban areas $(\mathrm{PR}=1.329 ; 95 \% \mathrm{CI}, 0.810-2.183)$ Table 3 . Also, children from the three regions of the North were about $16 \%$ less likely to be concurrently stunted and overweight against children from the Sourthern part. This reduced to about $0.4 \%$ after adjusting for other covariates. There was no statistically significant difference between mothers who were below the age of 20 and 20-34 $(\mathrm{PR}=1.002$; 95\% CI, 0.995-1.009) and 35-49 $(\mathrm{PR}=1.002$; 95\% CI, 0.993-1.012). Children with mothers aged 20-34 and 35-49 compared to those less than 20 years had more rates $(\mathrm{aPR}=1.001 ; 95 \% \mathrm{CI}, 0.994-1.005$ and $\mathrm{aPR}=1.001$; 95\% CI, 0.998-1.012) respectively.

\section{Predictors of overweight with concurrent stunting with proximal factors}

There were no significant effect of the proximal factors on concurrent stunting and overweight at the 5\% level 
Table 2 Distribution of overweight with concurrent stunting according to the distal factors as well as the child's age and sex with their corresponding unadjusted and adjusted prevalence ratios

\begin{tabular}{|c|c|c|c|c|}
\hline Variables & Level & Frequency (\%) & Crude PR (95\% CI) & Adjusted PR (95\% Cl) \\
\hline \multirow[t]{5}{*}{ Child's age in months } & $0-11$ & $1512(20.03)$ & Ref & Ref \\
\hline & $12-23$ & $1451(19.22)$ & $0.990(0.982-0.999)^{*}$ & $0.990(0.982-0.999)^{*}$ \\
\hline & $24-35$ & $1518(20.11)$ & $0.994(0.986-1.002)$ & $0.994(0.986-1.002)$ \\
\hline & $36-47$ & $1599(21.18)$ & $0.997(0.989-1.004)$ & $0.997(0.989-1.004)$ \\
\hline & $48-59$ & $1470(19.47)$ & $0.960(0.993-1.007)$ & $1.000(0.993-1.007)$ \\
\hline \multirow[t]{2}{*}{ Sex of child } & Male & $3859(51.11)$ & Ref & Ref \\
\hline & Female & $3691(48.89)$ & $0.754(0.495-1.149)$ & $1.003(0.998-1.009)$ \\
\hline \multicolumn{5}{|l|}{ Distal Factors } \\
\hline \multirow[t]{2}{*}{ Sex of household head } & Male & $5012(67.84)$ & Ref & Ref \\
\hline & Female & $2376(32.16)$ & $1.000(0.996-1.006)$ & $1.000(0.995-1.006)$ \\
\hline \multirow[t]{4}{*}{ Religion of household head } & Christian & $3623(47.99)$ & Ref & Ref \\
\hline & Muslim & $2376(31.47)$ & $1.084(0.661-1.770)$ & $0.997(0.990-1.004)$ \\
\hline & Traditional/ Spiritualist & $1070(14.17)$ & $1.147(0.613-2.145)$ & $0.997(0.989-1.006)$ \\
\hline & Other religion/ No Religion & $481(6.37)$ & $2.024(1.016-4.034)^{*}$ & $0.987(0.974-1.002)$ \\
\hline \multirow[t]{5}{*}{ Ethnicity of household head } & Akan & $1889(25.02)$ & Ref & Ref \\
\hline & Ga/Dangme & $281(3.72)$ & $1.004(0.990-1.018)$ & $1.002(0.988-1.012)$ \\
\hline & Ewe & $587(7.77)$ & $1.006(0.991-1.016)$ & $1.008(0.998-1.017)$ \\
\hline & Northern tribes & $4572(60.56)$ & $1.004(0.997-1.010)$ & $1.008(1.000-1.016)^{*}$ \\
\hline & Non-Ghanaian/ others & $221(2.93)$ & $0.995(0.976-1.015)$ & $0.997(0.975-1.020)$ \\
\hline \multirow[t]{4}{*}{ Maternal education } & None & $4081(54.05)$ & Ref & Ref \\
\hline & Primary & $1363(18.05)$ & $1.356(0.812-2.264)$ & $0.996(0.990-1.004)$ \\
\hline & Middle/JSS & 1565 (20.73) & $0.956(0.550-1.663)$ & $1.001(0.993-1.010)$ \\
\hline & Secondary + & $541(7.17)$ & $0.663(0.240-1.834)$ & $1.007(0.995-1.019)$ \\
\hline \multirow[t]{5}{*}{ Wealth index quintile } & Poorest & $3528(46.73)$ & Ref & Ref \\
\hline & Second & $1499(19.85)$ & $0.853(0.493-1.491)$ & $1.005(0.998-1.012)$ \\
\hline & Middle & $1045(13.84)$ & $0.945(0.513-1.743)$ & $1.004(0.995-1.012)$ \\
\hline & Fourth & $836(11.07)$ & $0.364(0.131-1.008)$ & $1.010(1.003-1.017)^{*}$ \\
\hline & Richest & $64298.50)$ & $0.970(0.460-2.044)$ & $1.000(0.984-1.014)$ \\
\hline \multicolumn{5}{|l|}{ Mosquito net utilization } \\
\hline \multirow[t]{2}{*}{ Mother and child slept under mosquito net last night } & Yes & $3268(43.28)$ & Ref & Ref \\
\hline & No & $4282(56.72)$ & $0.801(0.528-1.213)$ & $1.003(0.942-1.068)$ \\
\hline
\end{tabular}

* denotes statistical significance at $\mathrm{p}$ value $<0.05$

Christian comprise; Catholic, Pentecost, Deeper life, Jehovah witness, SDA and other Christian religions; Northern tribes - Comprise Guan, Gruma, Mole Dagbaani, Grusi and Mande

of significance. It was observed that breastfed children were $77 \%$ less likely to experience any concurrent stunting and overweight as against those who were not breastfed $(\mathrm{PR}=0.231 ; 95 \% \mathrm{CI}, 0.075-0.710)$. After adjusting for all the other variables, this group was 1.028 times more likely to be concurrently stunted and overweight than those not breastfed. Children with diarrhoea were $7 \%$ more likely to be classified under concurrent stunting and overweight than those without ( $\mathrm{PR}=1.069 ; 95 \% \mathrm{CI}, 0.606-1.886$ and $\mathrm{aPR}=1.027$; $95 \% \mathrm{CI}, 0.986,1.069)$, though both were statistically not significant.

\section{Discussion}

\section{Prevalence of overweight with concurrent stunting}

Concurrent stunting and overweight is a manifestation of the overweight with concurrent stunting in individuals. Previous analysis of the Ghana MICS4 data sets and other studies indicated the coexistence of overweight and stunting occurring at the national level [7, 41]. Similarly other previous studies from non-Ghanaian settings had showed the co-existence of overweight with concurrent stunting at the household and individual levels $[16,18,21,23,51,52]$. Overall, $1.2 \%$ of Ghanaian children 
Table 3 Distribution of overweight with concurrent stunting according to the intermediate factors with their corresponding unadjusted and adjusted prevalence ratios

\begin{tabular}{|c|c|c|c|c|}
\hline Variables & Level & Frequency (\%) & Crude PR (95\% Cl) & Adjusted PR (95\% Cl) \\
\hline \multicolumn{5}{|l|}{ Intermediate factors } \\
\hline \multirow[t]{4}{*}{ Sources of drinking water } & Pipe water & $2538(34.35)$ & Ref & Ref \\
\hline & Tube Well, Borehole, Tanker & $2308(31.24)$ & $1.002(0.996-1.008)$ & $0.994(0.986-1.002)$ \\
\hline & River, Spring and other water bodies & $946(12.80)$ & $0.996(0.987-1.005)$ & $1.001(0.997-1.005)$ \\
\hline & Bottled Water, Sachet Water & $1596(21.60)$ & $1.003(0.997-1.010)$ & $0.995(0.986-1.003)$ \\
\hline \multirow[t]{3}{*}{ Marital status } & Currently married & $4654(63.51)$ & Ref & Ref \\
\hline & Formerly married & $587(8.01)$ & $1.003(0.994-1.011)$ & $0.989(0.957-1.022)$ \\
\hline & Never married & $2087(28.48)$ & $0.996(0.990-0.998)^{*}$ & $0.992(0.981-0.997)^{*}$ \\
\hline \multirow[t]{3}{*}{ Maternal age at child birth } & Less than 20 & $1400(18.54)$ & Ref & Ref \\
\hline & $20-34$ & $5226(69.22)$ & $1.002(0.995-1.009)$ & $1.001(0.994-1.005)$ \\
\hline & $35-49$ & $924(12.24)$ & $1.002(0.993-1.012)$ & $1.001(0.998-1.012)$ \\
\hline \multirow[t]{2}{*}{ Type of birth } & Twin & $296(3.92)$ & Ref & Ref \\
\hline & Single & $7254(96.68)$ & $1.000(0.992-1.026)$ & $1.009(0.984-1.034)$ \\
\hline \multirow[t]{3}{*}{ Size of child at birth } & Large & $825(43.13)$ & Ref & Ref \\
\hline & Average & $870(45.48)$ & $1.004(0.998-1.010)$ & $1.004(0.997-1.010)$ \\
\hline & Small & $218(11.40)$ & $1.001(0.991-1.012)$ & $1.001(0.990-1.012)$ \\
\hline \multirow[t]{4}{*}{ Birth order } & 1 & $2127(28.17)$ & Ref & Ref \\
\hline & $2-3$ & $2973(39.83)$ & $1.000(0.993-1.006)$ & $0.997(0.991-1.002)$ \\
\hline & $4-6$ & $1919(25.42)$ & $1.002(0.996-1.010)$ & $0.995(0.987-1.003)$ \\
\hline & $7+$ & $531(7.03)$ & $1.001(0.991-1.012)$ & $1.000(0.996-1.014)$ \\
\hline \multirow[t]{2}{*}{ Area of residence } & Urban & $2117(28.04)$ & Ref & Ref \\
\hline & Rural & $5433(71.96)$ & $1.329(0.810-2.183)$ & $1.001(0.997-1.034)$ \\
\hline \multirow[t]{3}{*}{ Geographic zones } & Coastal/southern Zone & $1806(23.92)$ & Ref & Ref \\
\hline & Middle zone & $1624(21.51)$ & $0.872(0.480-1.581)$ & $1.011(1.000-1.014)^{*}$ \\
\hline & Northern zone & $4120(54.57)$ & $0.817(0.500-1.336)$ & $1.012(0.998-1.026)$ \\
\hline \multirow[t]{2}{*}{ Three northern and non-northern regions } & All but three northern regions & $2551(33.79)$ & Ref & Ref \\
\hline & Three northern regions & $4999(66.21)$ & $0.848(0.552-1.302)$ & $0.996(0.986-1.001)$ \\
\hline
\end{tabular}

under five were concurrently overweight and stunted. This prevalence determined by the current study was low compared to previous studies that assessed DBM in children under five living in developing countries [21-23, 41]. Adel et al. who conducted a population based survey on the nutritional status of under-fives in Libya reported the prevalence of DBM to be 7\%. Popkin, et al. [22] who similarly examined the relationship between stunting and overweight status for Russian, Brazillian, South African and Chinese children reported a significant association between stunting and overweight status in children of all countries, which showed an income adjusted risk ratios of being overweight for a stunted child as being ranged from 1.7 to 7.8 . Fernald et al. [23] reported the prevalence of overweight with concurrent stunting among rural low-income Mexican pre-school children was approximately $5 \%$ in non- indigenous children, and over $10 \%$ in indigenous children. A nationwide study conducted by Masibo et al., [53] among Kenyan children under-fives revealed an evident emergence DBM demonstrated by stunted and underweight children whose mothers are overweight. Similarly, Provo's [18] study using Demographic Health Survey (DHS) data from Eastern, Middle, Southern, and Western Africa also revealed high prevalence of Double Burden of Malnutrition (DBM).

According to Kimani-murage et al., [17], the DBM is evident in societies undergoing nutrition transition especially in LMICs. This compares with Ghana since its declaration of being a middle income country [54]. Nutrition transition characterizes the shift in disease patterns towards nutrition-related NCD's, which is associated with changes in behaviors, lifestyles, diets, physical inactivity, smoking and alcohol consumption [55]. 
Table 4 Distribution of overweight with concurrent stunting according to their proximal factors with their corresponding unadjusted and adjusted prevalence ratios

\begin{tabular}{|c|c|c|c|c|}
\hline Variables & Level & Frequency (\%) & Crude PR $(95 \%$ Cl) & Adjusted PR (95\% Cl) \\
\hline \multicolumn{5}{|l|}{ Proximal factors } \\
\hline \multicolumn{5}{|l|}{ Breastfeeding status } \\
\hline \multirow[t]{2}{*}{ Child ever been breastfed } & Yes & $7484(99.17)$ & $0.231(0.075-0.710)$ & $1.028(0.956-1.105)$ \\
\hline & No & $63(0.83)$ & Ref & Ref \\
\hline \multicolumn{5}{|l|}{ Child health status } \\
\hline \multirow[t]{2}{*}{ Child with diarrhoea } & Yes & $1126(14.92)$ & $1.069(0.606-1.886)$ & $1.027(0.986-1.069)$ \\
\hline & No & $6422(85.08)$ & Ref & Ref \\
\hline \multirow[t]{2}{*}{ Child with cough } & Yes & $1672(22.15)$ & $0.717(0.412-1.246)$ & $1.048(0.993-1.106)$ \\
\hline & No & $5876(77.85)$ & Ref & Ref \\
\hline \multirow[t]{2}{*}{ Child given Vitamin A dose within last 6 months } & Yes & $2269(30.65)$ & $0.925(0.591-1.447)$ & \\
\hline & No & $5134(69.35)$ & Ref & Ref \\
\hline \multirow[t]{2}{*}{ Child taken to a health facility during illness } & Yes & $893(78.06)$ & $1.669(0.202-13.809)$ & $1.001(0.928-1.092)$ \\
\hline & No & $251(21.94)$ & Ref & Ref \\
\hline \multirow[t]{2}{*}{ Child ever received any vaccinations } & Yes & $1211(90.31)$ & $0.517(0.153-1.749)$ & $0.961(0.912-1.012)$ \\
\hline & No & $130(9.69)$ & Ref & Ref \\
\hline \multirow[t]{2}{*}{ Anaemia status } & Normal & $1535(33.98)$ & Ref & Ref \\
\hline & Anaemia & $2882(66.02)$ & $0.920(0.518-1.632)$ & $1.025(0.931-1.128)$ \\
\hline
\end{tabular}

\section{Individual and contextual determinants of overweight with concurrent stunting Individual determinants}

Previous studies have reported that the sex of a child is a significant determinant of DBM. Our analysis revealed that female children tended to experience more DBM than their male counterparts although this was not statistically significant after adjusting for various covariates - as inMasibo and Makoka [53] and Provo [18]. Children between 12 and 23 months and 24-35 months recorded the highest prevalence of DBM with children below one year recording the least $(0.1 \%)$. In general, there was a non-significant reduction in prevaelence ratios as ages in months increased. Kroker-lobos et al. had previously reported similarily observed data [56].

The current analysis identified a number of contextual predictors of concurrent overweight and stunting in Ghanaian children. The significantly associated factors are wealth index quintile, belonging to either no religion or other religions, and and geographic zones. Compared to the poorest wealth index quintile, children belonging to the fourth index quintile had a significantly decreased rates of concurrent overweight and stunting but after adjusting for factor specific and the hierarchical levels an increased rates of concurrent overweight and stunting was observed. This study agreed with Fernald [23] conclusion that children living in lower SES were more exposed to the occurrence of concurrent overweight and stunting. Mothers who were educated at the secondary level or higher had a higher increased rates of concurrent overweight and stunting though insignificant. The prevalence of the concurrent overweight and stunting could be associated to lower educational levels and socioeconomic status of women, which are determinants of poor nutrition practices in developing countries where children under five are mostly affected [24]. Children belonging to mothers between 25 and 34 and 35-49 years were $0.1 \%$ more likely when compared to 15-19 years to be overweight and concurrently stunted. This could imply that nutrients needed by adolescent mothers, for optimum growth and development are been competed for especially during pregnancy and lactation. This competition for nutrients especially iron could predispose the adolescent mother to micronutrient deficiency. This micronutrient deficiency affects uterine development and further result in the birth of a low weight baby who may be predisposed to chronic illness and may eventually lead to the onset of DBM. Additionally, Adair et al., indicated that, "Low Birth weight (LBW) infants tend to have greater adult lean mass and human capital when they experience rapid weight gains still in the first one thousand days of life." The same study associated weight gains in later life to adverse cardiovascular consequences [57].

Rural children were 33\% (unadjusted) and 1\% (adjusted) more more likely to experience concurrent stunting and overweight compared to their urban counterparts. This compares favorably with thefindings of Oddo et al., (2012) where DBM was not exclusive to urban areas. Their recommendation that future policies and interventions should address DBM in both rural 


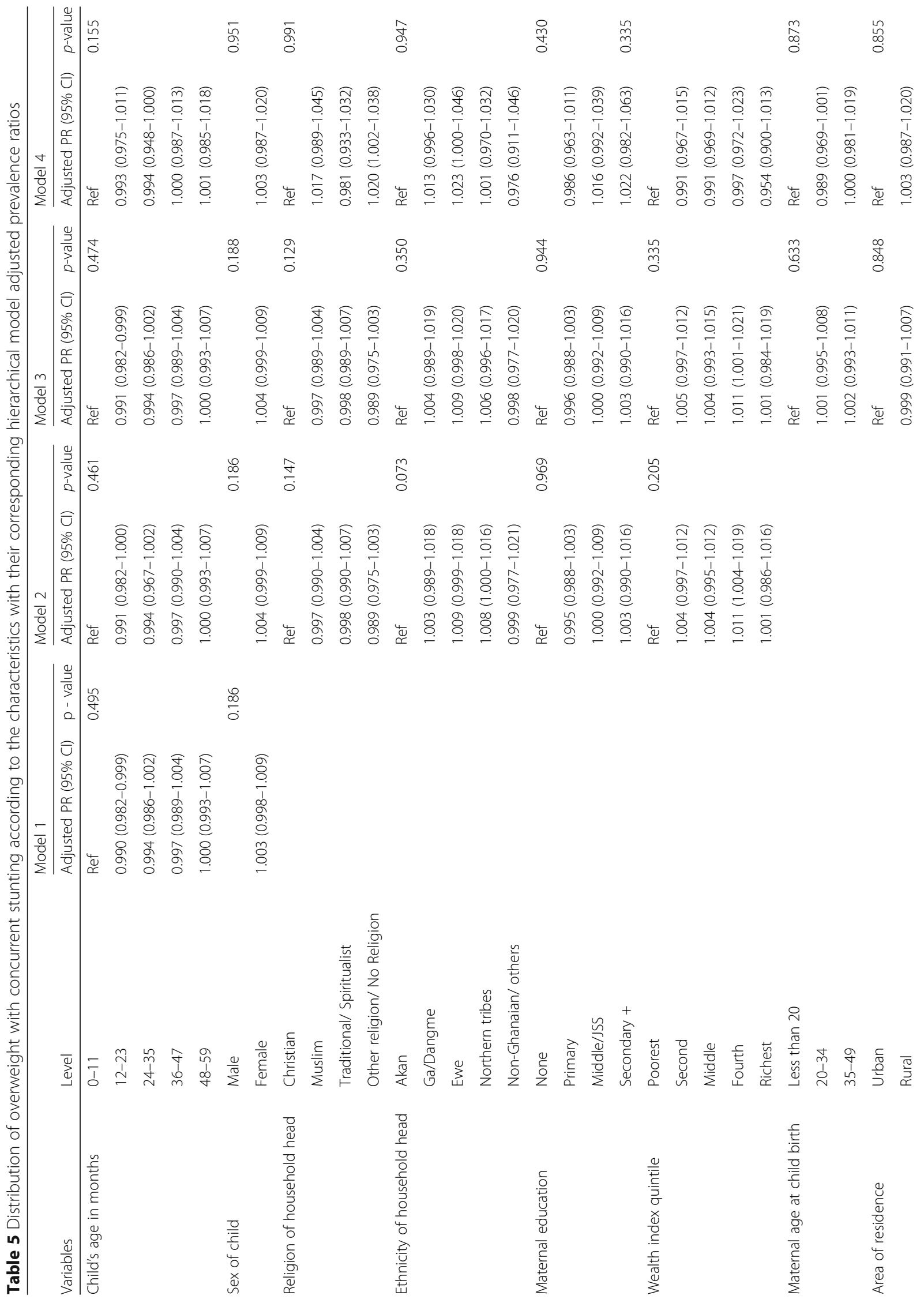




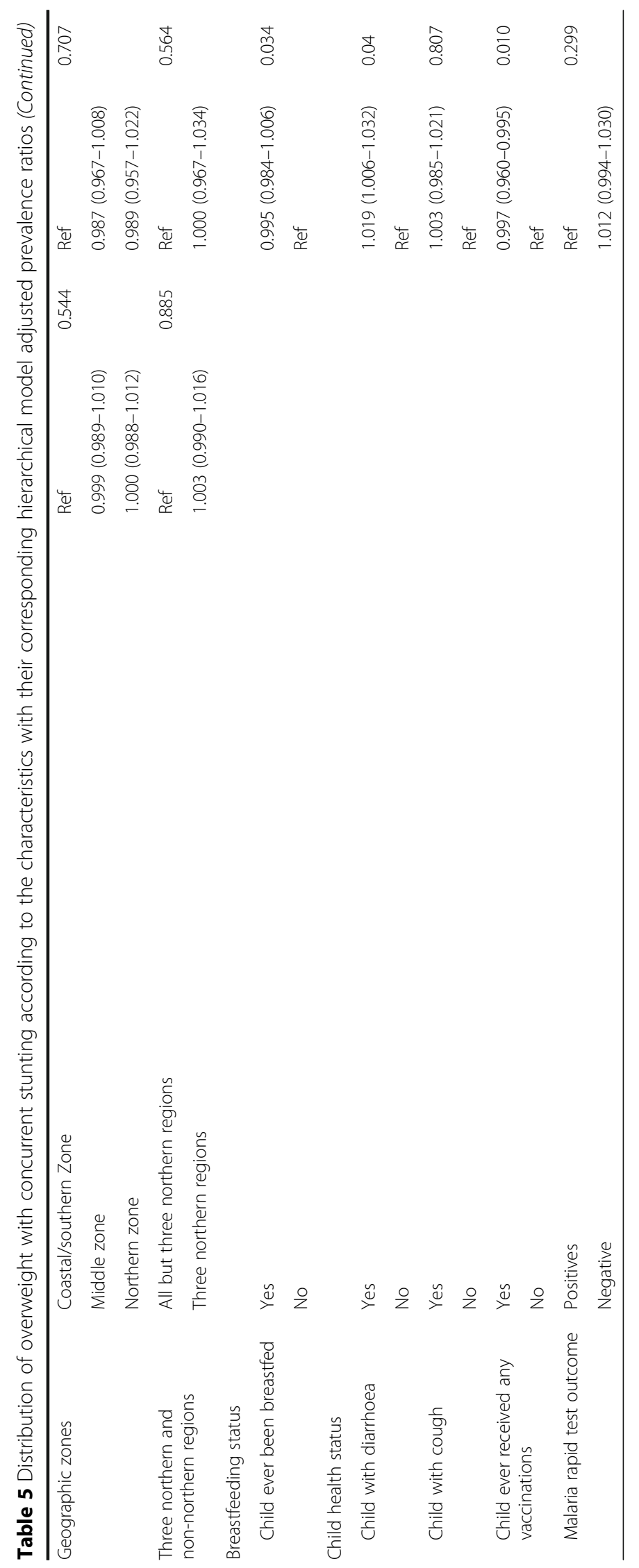


and urban developing country settings are relevant in our context.

\section{Study strength and weakness}

A major strength of this study, is the analytic method used. The Ghana MICS stopped at the univariate level but this study went beyond just looking at Univariate and explored both bivariate and multivariable analysis. The Poison regression model was used due to its advantage over the logistic model to determine associations between the outcome (dichotomous) and the predictor variables. An important limitation of this study is that strong conclusions could not be cannot be drawn with respect to the causes of DBM. This is because the original survey [7], from which our paper metamorphoses did not assess certain key variables that are potentially linked to the nutritional status of the under-five children. Also due to the cross-sectional design of the survey, no causal linkages can be inferred.

\section{Conclusions}

This analysis determined the prevalence of concurrent stunting and overweight among Ghanaian children to be $1.2 \%$. Four contextual variables (breastfeeding status, religion, geographic region, and wealth index quintile) were associated with overweight with concurrent stunting. After factor-specific adjustments of prevalence ratios, not belonging to any religion was associated with a marginally reduced likelihood of experiencing concurrent stunting and overweight. Compared to the poorest quintile, children belonging to the fourth wealth quintile had significantly increased rates of overweight with concurrent stunting. Intermediate level predictor of overweight with concurrent stunting was geographic region. Children from the three northern regions were about $16 \%$ less likely to be concurrently stunted and overweight against children from the Sourthern part. This was, however, significantly reduced after adjusting for other covariates. With the exception of breastfeeding, the current analysis did not reveal significant proximal level predictors of overweight with concurrent stunting. Breastfed children were $77 \%$ less likely to experience any concurrent stunting and overweight compared to those who were not breastfed. We conclude that, only contextual factors are predictive of DBM among children under five living in Ghana.

\footnotetext{
Abbreviations

BMI: Body mass index; BMIZ: Body mass index Z - scores; Cl: Confidence interval; DBM: Double/ dual burden of malnutrition; DHS: Ghana demographic health survey; GSS: Ghana statistical service; HAZ: Height for age Z - score; JSS: Junior High School; LMIC's: Low and middle income countries; MICS: Multiple indicator cluster survey; MICS4: Fourth round of the multiple indicator cluster survey; NCD: Non-Communicable diseases; NHIS: National health insurance scheme; PPS: Probability proportional sample; PR: Prevalence ratio; PSUs: Primary sampling units;

SES: Socioeconomic status; SSUs: Secondary sampling units; WAZ: Weight for Age Z - score; WHO: World Health Organization
}

\section{Acknowledgements}

We thank UNICEF for availing the MICS4 data sets for analysis. We acknowledge the inputs of Dr. Ireneous Soyiri's during the conception phase of the analysis.

\section{Funding}

Authors did not receive any funding for this research.

\section{Availability of data and materials}

Our analysis is done of a publicly available and accessible nationally representative survey (Ghana MICS). We would like to emphasize that we do not have special access privileges to these data and that interested researchers may apply to access the data at this site http://mics.unicef.org/surveys.

\section{Authors' contributions}

AKL conceived the idea and discussed with BKA, and CG for inputs. BKA put up the framework. AKL developed the initial analysis plan and guided BKA in the data analysis. BKA, and AKL drafted different sections of the manuscript. CG re-analysed the data and wrote the results section in response to important queries from reviewers. CG provided inputs in the revision of the manuscript. All authors read and approved the final version of the manuscript.

\section{Ethics approval and consent to participate}

Ethical approval for the Multiple Indicator Cluster Survey (MICS) was obtained from the Ghana Health Service. The current paper made use of the secondary data from the MICS. The data sets, is publicly available. Request for the use of the datsets was granted by the United Nations Children's Emergency Fund.

Consent for publication

Not applicable.

\section{Competing interests}

The authors declare that they have no competing interests.

\section{Publisher's Note}

Springer Nature remains neutral with regard to jurisdictional claims in published maps and institutional affiliations.

\section{Author details}

${ }^{1}$ Department of Population, Family and Reproductive Health, School of Public Health, College of Health Sciences, University of Ghana, Accra, Ghana. ${ }^{2}$ Department of Biostastics, School of Public Health, College of Health Sciences, University of Ghana, Accra, Ghana.

Received: 9 January 2016 Accepted: 19 July 2017

Published online: 27 July 2017

\section{References}

1. Md O, Blössner M. The World Health Organization global database on child growth and malnutrition : methodology and applications. Int J Epidemiol. 2003;32:518-26.

2. Nube M. Relationships between undernutrition prevalence among children and adult women at national and subnational level. Eur J Clin Nutr. 2005;59:1112-20.

3. Cristina V, Vieira R. Stunting : its relation to overweight, global or localized adiposity and risk factors for chronic non-communicable diseases Deficit estatural : relações com sobrepeso, adiposidade global ou localizada e fatores de risco para doenças crônicas não- transm. Rev Bras Saude Mater Infant. 2007;7(4):365-72.

4. Langley-Evans SC. Nutritional programming of disease: Unravelling the mechanism. J Anat. 2009;215:36-51.

5. Brett K, Ferraro Z, Yockell-Lelievre J, Gruslin A, Adamo K: Maternal-fetal nutrient transport in pregnancy pathologies: the role of the placenta. 2014; 15:16153-16185.

6. Jesus GMD, Vieira GO, Vieira TO, Martins CDC, Mendes CM, Castelão ES. Determinants of overweight in children under 4 years of age. Jornal de Pediatria. 2010;86(4):311-6.

7. Ghana Statistical S: Multiple indicator cluster survey with an enhanced malaria module and biomarker. 2011.

8. Appiah CA, Steiner-asiedu M, Otoo GE. Predictors of overweight / obesity in Urban Ghanaian Women. Int J Clin Nutr. 2014;2(3):60-8. 
9. Jehn $\mathrm{M}$, Brewis $\mathrm{A}$. Economics and human biology paradoxical malnutrition in mother - child pairs : untangling the phenomenon of over- and undernutrition in underdeveloped economies. Econ Hum Biol. 2009;7:28-35.

10. Agyei-Mensah S, de-Graft Aikins A. Epidemiological transition and the double burden of disease in Accra, Ghana. J Urban Health. 2010;87(5):879-97.

11. Mamabolo RL, Alberts MSNP, Delemarre-van de Waal HA, Levitt NS. Prevalence and determinants of stunting and overweight in 3-year-old black South African children residing in the Central Region of Limpopo Province, South Africa. Public Health Nutr. 2005;8(5):501-8.

12. Frempong GA: Perceived body weightand actual Body Mass Index (BMI) Among urban poor communities in Accra, Ghana. 2013.

13. Bourne LT, Langenhoven ML, Steyn $K$, Jooste PL, Laubscher JA, Bourne DE: Nutritional status of 3-6 year-old African children in the Cape peninsula. 1994;71:695-702.

14. Doak CM, Adair LS, Bentley M, Monteiro C, Popkin BM. The dual burden household and the nutrition transition paradox. Int J Obes. 2005;29(1):129-36.

15. Florêncio TM, Ferreira HS, de França AP, Cavalcante JC, Sawaya AL. Obesity and undernutrition in a very-low-income population in the city of Maceió, northeastern Brazil. Br J Nutr. 2001;86(2):277-84.

16. Garrett J, Ruel MT. The coexistence of child undernutrition and maternal overweight: prevalence, hypotheses, and programme and policy implications. Maternal \& child nutrition. 2005;1(3):185-96.

17. Kimani-murage EW, Kahn K, Pettifor JM, Tollman SM, Dunger DB, Gómezolivé XF, Norris SA. The prevalence of stunting, overweight and obesity, and metabolic disease risk in rural South African children. BMC Public Health. 2010;10:1-13.

18. Provo AM. Towards Sustainable Nutrition for All Tackling the double burden of malnutrition in Africa. Sight Life. 2013;27(3):40-8.

19. Steyn K, Bourne L, Jooste P, Fourie JM, Rossouw K, Lombard C. Anthropometric profile of a black population of the Cape Peninsula in South Africa. East African Med J. 1998;75(1):35-40.

20. Wibowo $Y$, Sutrisna B, Hardinsyah $H$, Djuwita R, Korib MM, Syafiq A, Tilden A, Najib M. Relationship between intra-household food distribution and coexistence of dual forms of malnutrition. Nutr Res Pract. 2015;9(2):174.

21. Urke HB, Mittelmark MB, Valdivia M. Trends in stunting and overweight in Peruvian pre-schoolers from 1991 to 2011 : findings from the Demographic and Health Surveys. Public Health Nutr. 2014;17(11):2407-18.

22. Popkin BM, Richards MK, Montiero CA. Stunting is associated with overweight in children of four nations that are undergoing the nutrition transition. J Nutr. 1996;126(12):3009.

23. Fernald LC, Neufeld LM. Overweight with concurrent stunting in very young children from rural Mexico: prevalence and associated factors. Eur J Clin Nutr. 2007;61(5):623-32.

24. Bain LE, Awah PK, Geraldine N, Kindong NP, Sigal Y, Bernard N, Tanjeko AT. Malnutrition in Sub-Saharan Africa: burden, causes and prospects. Pan Afr Med J. 2013;15:120.

25. de Onis M, Blössner M, Borghi E, Morris R, Frongillo EA. Methodology for estimating regional and global trends of child malnutrition. Int J Epidemiol. 2004;33(6):1260-70.

26. De Haas H. Migration and development: a theoretical perspective. Int Migr Rev. 2008:44:227-64

27. Paulo S, Hoffman DJ, Sawaya AL, Verreschi I, Tucker KL, Roberts SB. Why are nutritionally stunted children at increased risk of obesity? Studies of metabolic rate and fat oxidation in shantytown children. Am J Clin Nutr. 2000:702-7.

28. Keino S, Plasqui G, Ettyang G, van den Borne B. Determinants of stunting and overweight among young children and adolescents in sub-Saharan Africa. Food Nutr Bull. 2014;35(2):167-78.

29. Bhandari TR, Chhetri M. Nutritional status of under five year children and factors associated: a study in Kapilvastu District, Nepal. J Nutr Health Food Sci. 2011:1-6.

30. Hong R, Banta JE, Betancourt JA. Relationship between household wealth inequality and chronic childhood under-nutrition in Bangladesh. Int J Equity Health. 2006;5:15.

31. Shamah-levy T, Nasu LC, Moreno-macias H, Monterrubio-flores E, Avila-arcos MA. maternal characteristics determine stunting in children of less than five years of age results from a national probabilistic survey. Clin Med. 2008;1:43-52.

32. Strauss RS, Knight J. Influence of the home environment on the development of obesity in children. J Am Acad Pediatr. 1999;103(e85):1-8.

33. Danielzik S, Czerwinski-Mast M, Langnäse K, Dilba B, Müller MJ. Parental overweight, socioeconomic status and high birth weight are the major determinants of overweight and obesity in 5-7 y-old children: baseline data of the Kiel Obesity Prevention Study (KOPS). Intl J Obes Relat Metab Disord. 2004;28(11):1494-502.

34. Mo-suwan $L$, Tongkumchum $P$, Puetpaiboon A. Determinants of overweight tracking from childhood to adolescence: a 5 y follow-up study of Hat Yai schoolchildren. Intl J Obes Relat Metab Disord. 2000;24(12):1642-7.

35. Crepinsek B. Maternal employment and children's nutrition. food assistance \& nutrition research program, vol. 1; 2004.

36. Dwyer JT, Feldman JJ, Mayer J. The social psychology of dieting. J Health Soc Behav. 2014;11(4):269-87.

37. Gonzalez-Casanova I, Sarmiento OL, Pratt M, Gazmararian JA, Martorell R, Cunningham SA, Stein A. Predictors of overweight and obesity among Colombian children and. Ctr Dis Control Prev. 2005;2014:1-12.

38. Kruger R, Kruger HS, Macintyre UE. The determinants of overweight and obesity among 10- to 15-year-old schoolchildren in the North West Province, South Africa - the THUSA BANA (Transition and Health during Urbanisation of South Africans; BANA, children) study. Public Health Nutr. 2006;9(3):351-8.

39. Steyn NP, Ph D, Labadarios D, Ch B, Maunder E, Nel J, Lombard C, Consumption F. Secondary anthropometric data analysis of the national food consumption survey in South Africa : the double burden. Nutr J. 2005;21:4-13.

40. Corvalán C, Gregory CO, Ramirez-Zea M, Martorell R, Stein AD. Size at birth, infant, early and later childhood growth and adult body composition: a prospective study in a stunted population. Int J Epidemiol. 2007;36(3):550-7.

41. Adel ET, Marie-Françoise RC, Salaheddin MM, Najeeb E, Abdel Monem A, Ibrahim B, Lenoir G. nutritional status of under-five children in libya; a national population-based survey Libyan J Med, AOP : 071006. Libyan J Med. 1995:13-9.

42. Corsi DJ, Finlay JE, Subramanian S. Global burden of double malnutrition: has anyone seen it? PLoS One. 2011;6(9):e25120.

43. Shrimpton RRC. The Double Burden of Malnutrition: A Review of Global Evidence. World Bank; 2012. Accessed from https://doi.org/10.1596/27417. Accessed 12 Oct 2016

44. Tzioumis E, Adair LS. Childhood dual burden of under-and overnutrition in low-and middle-income countries: a critical review. Food Nutr Bull. 2014; 35(2):230-43.

45. Adekanmbi VT, Kayode GA, Uthman OA. Individual and contextual factors associated with childhood stunting in Nigeria: a multilevel analysis. Matern Child Nutr. 2013:9:244-59.

46. Boyce SP, Walters T, Nyaku A: Contextual analysis of undernutrition outcomes and anaemia: Ghana. 2014: 4-5.

47. Galiano LP, Abril FM, Ernert A, Bau AM. The double burden of malnutrition and its risk factors in school children in Tunja. Archivos latinoamericanos de nutrición. 2012;62(2):119.

48. Wondimagegn ZT. Magnitude and determinants of stunting among children in Africa : a systematic review. Curr Res Nutr Food Sci. 2014;2(2):88-93.

49. Hien NN, Hoa NN. Nutritional status and determinants of malnutrition in children under three years of age in Nghean, Vietnam. Pak J Nutr. 2009; 8(7):958-64.

50. Victora CG, Huttly SR, Fuchs SC, Olinto M. The role of conceptual frameworks in epidemiological analysis: a hierarchical approach. Int J Epidemiol. 1997;26(1):224-7.

51. Rivera JA, Pedraza LS, Martorell R, Gil A, Double A: The complexity of the double burden of malnutrition : new evidence from Latin America Burden of Malnutrition Research Group Center for Nutrition and Health Research, National Institute of Public Health, Cuernavaca, Mexico Department of Biochemistry and. 2014:1-2.

52. Said-Mohamed R, Allirot $X$, Sobgui M, Pasquet P. Determinants of overweight associated with stunting in preschool children of Yaounde, Cameroon. Ann Hum Biol. 2009;36(2):146-61.

53. Masibo PK, Makoka D. Trends and determinants of undernutrition among young Kenyan children: Kenya Demographic and Health Survey; 1993, 1998, 2003 and 2008-2009. Public Health Nutr. 2012;15(09):1715-27.

54. Duffour K: Ghana now a lower middle income country. 2011.

55. Amuna P, Zotor FB. Epidemiological and nutrition transition in developing countries: impact on human health and development. Proc Nutr Soc. 2008;67(01):82-90

56. Kroker-lobos MF, Pedroza-tob A, Pedraza LS, Rivera JA. The double burden of undernutrition and excess body weight in Mexico. Am J Clin Nutr. 2014;100(1):1652-8

57. Adair LS, Guilkey DK. Age-specific determinants of stunting in Filipino children. J Nutr. 1997:127:314-20. 